\title{
Investigation and design of monitoring systems in real time landslides at Xekaman 3 hydropower plant
}

\author{
Khai Cong Pham 1, ${ }^{*}$, Hai Van Nguyen ${ }^{2}$ \\ ${ }^{1}$ Faculty of Geomatics and Land Administration, Hanoi University of Mining and Geology, Vietnam \\ 2 Faculty of Water Resources Engineering, ThuyLoi University - Second Base, Vietnam
}

ARTICLE INFO ABSTRACT

Article history:

Received 18 ${ }^{\text {th }}$ Oct 2019

Revised 3rd Sept. 2020

Accepted 28 ${ }^{\text {th }}$ Feb. 2020

Keywords:

Continuously Operating

Reference Station (CORS),

Landslides,

Real-time monitoring,

Xekaman 3 hydropower plant.
This paper presents results of investigating, designing, and building a monitoring system in real-time based on GNSS CORS technology in order to monitor landslides at Xekaman 3 hydropower plant in the Lao people's Democratic Republic. A system with 18 monitoring stations and a CORS station has been designed to ensure the operation of system 24/7. The connection diagram for data transmission from the monitoring stations to the data processing center, as well as the connection diagram of the devices at a monitoring station has been designed. A simulation experiment has shown that the designed system can be applied for realtime monitoring of landslide.

Copyright (C) 2020 Hanoi University of Mining and Geology. All rights reserved.

${ }^{*}$ Corresponding author

E-mail: phamcongkhai@humg.edu.vn

DOI: 10.46326/JMES.2020.61(1).02 


\title{
Tạp chí Khoa học Kỹ thuật Mỏ - Địa chất
}

\section{Nghiên cứu thiết kế hệ thống quan trắc trượt lở đất đá theo thời gian thực ở nhà máy thủy điện Xekaman 3}

\author{
Phạm Công Khải $1{ }^{*}$, Nguyễn Văn Hải ${ }^{2}$ \\ ${ }^{1}$ Khoa Trắc địa - Bản đồ và Quản lý đất đai, Trường Đại học Mỏ - Địa chất, Việt Nam \\ ${ }^{2}$ Khoa Kỹ thuật Tài nguyên nước, Đại học Thủy Lợi - Cơ sở 2, Việt Nam
}

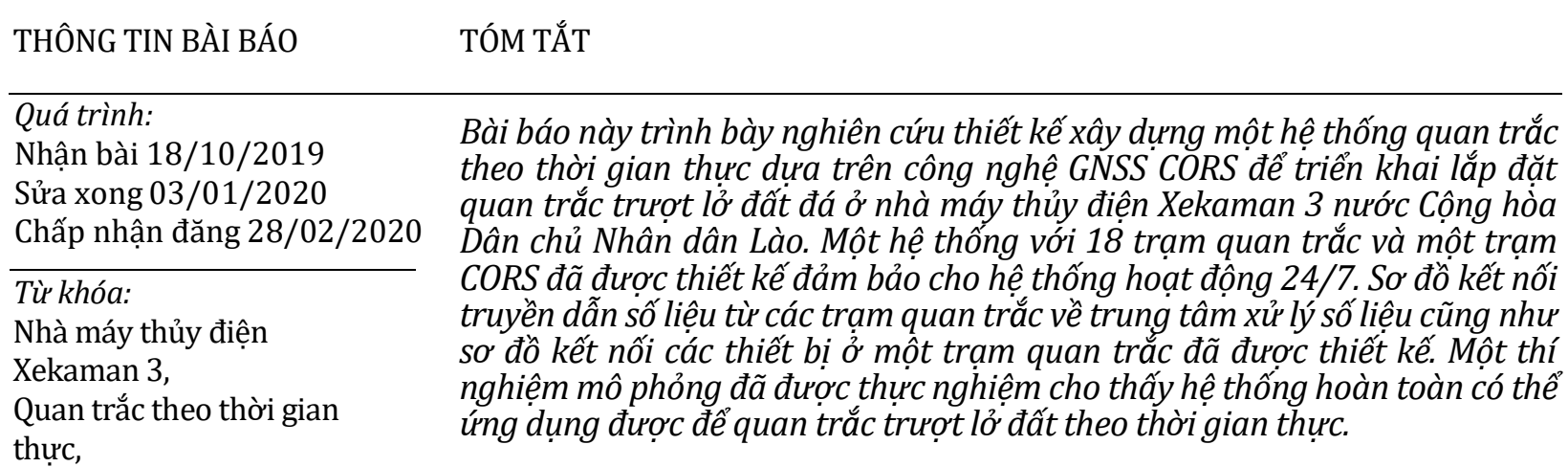

Trạm tham chiếu hoạt động liên tục (CORS),

Trượt lở đất đá.

C 2020 Trường Đại học Mỏ - Địa chất. Tất cả các quyền được bảo đảm.

\section{Mở đầu}

Trượt lở đất đá (landslides) là một dạng tai biến tự nhiên xảy ra tương đối phổ biến ở vùng đồi núi hoặc ở khu vực khai thác khoáng sản do làm mất thế cân bằng của khối đất đá. Nó làm cho một khối lượng lớn đất đá dịch chuyển xuống phía dưới, bao phủ trong một phạm vi rộng lớn, gây ra những thiệt hại rất nặng nề về người và tài sản, gây nên suy thoái môi trường (Savvaidis, 2016). Quan trắc chuyển dịch bề mặt mái dốc sẽ cung cấp được những thông tin rất có giá trị của hiện tượng trượt lở như độ lớn, vận tốc, gia tốc của chuyển dịch. Những thông tin này nếu được phát hiện sớm

\section{${ }^{*}$ Tác giả liên hệ}

E - mail: phamcongkhai@humg.edu.vn DOI: 10.46326/JMES.2020.61(1).02 sẽ giảm thiểu được những tổn thất có thể xảy ra. Một trong những chiến lược giảm thiểu rủi ro do trượt lở đất đá gây ra là phải có hệ thống quan trắc theo thời gian thực và cảnh báo tức thời $(\mathrm{Vu}$ Van Khoa, Shigeru, 2018). Đã có nhiều giải pháp kỹ thuật đã được đề xuất để quan trắc trượt lở đất đá bằng hệ thống các cảm biến gắn vào khối trượt (Georgieva et al., 2015; Kuang \& Cao, 2015). Hệ thống định vị toàn cầu GPS đã được nghiên cứu ứng dụng để quan trắc trượt lở cho khu định cư nhà máy thủy điện (Ruya, Xiufeng, 2013) cho thấy: sai số quan trắc dịch chuyển ngang là $2 \mathrm{~mm}$ và sai số dịch chuyển đứng là $4 \mathrm{~mm}$. Các phương pháp như sử dụng máy toàn đạc điện tử (Serena Artese, Michele Perrelli, 2018), máy quét lazer mặt đất (Irwan, et al., 2017), công nghệ GNSS và kỹ thuật viễn thám (Tommaso et al., 2019) cũng đã được sử dụng trong việc quan trắc trượt lở đất đá . 
Mỗi phương pháp đều có những ưu và nhược điểm cũng như khả năng áp dụng của nó. Tuy nhiên có một đặc điểm chung của các phương pháp trên để quan trắc trượt lở là vẫn chưa thực sự quan trắc được theo thời gian thực, nên chưa thể cảnh báo tức thời.

Nhà máy thủy điện Xekaman 3 được xây dựng và đưa vào vận hành từ năm 2013 , tuy nhiên vào năm 2016 đã xảy ra sự cố trượt lở mái dốc làm phá hủy đường ống dẫn nước vào tổ máy và gây ra nhiều thiệt hại khác. Ở nhà máy đã bố trí một hệ thống quan trắc trượt lở bằng máy toàn đạc điện tử, tuy vậy đây cũng là quan trắc theo chu kỳ, do đó không thể đưa ra cảnh báo một cách tức thời.

Bài báo này trình bày nghiên cứu thiết kế, xây dựng một hệ thống quan trắc theo thời gian thực trượt lở đất đá mái dốc ở nhà máy thủy điện Xekaman 3.

\section{Nguyên lý hoạt động của hệ thống quan trắc chuyển dịch theo thời gian thực}

Nguyên lý hoạt động của hệ thống quan trắc dịch chuyển biến dạng cầu theo thời gian thực được dựa trên nguyên lý hoạt động của hệ thống GNSS/CORS (Hình 1). Tín hiệu vệ tinh GNSS được ăngten (1) thu nhận, truyền về bộ thu GNSSNetS8+ thông qua một dây cáp chuyên dụng. Tại đây, tín hiệu vệ tinh được giải mã và đi qua modem (3) về máy tính chủ (4). Thông qua máy tính chủ được kết nối với một đường truyền Internet có một địa chỉ IP tĩnh, có thể phân cấp quản lý, tùy theo từng đối tượng người sử dụng bằng hai phần mềm đi kèm: NRS - Station (phục vụ tính toán số liệu, phân bổ số liệu trạm thu tĩnh) và NRS - Server cung cấp thông tin sai phân cho điểm đo di động, xử lý số liệu của mạng lưới đo

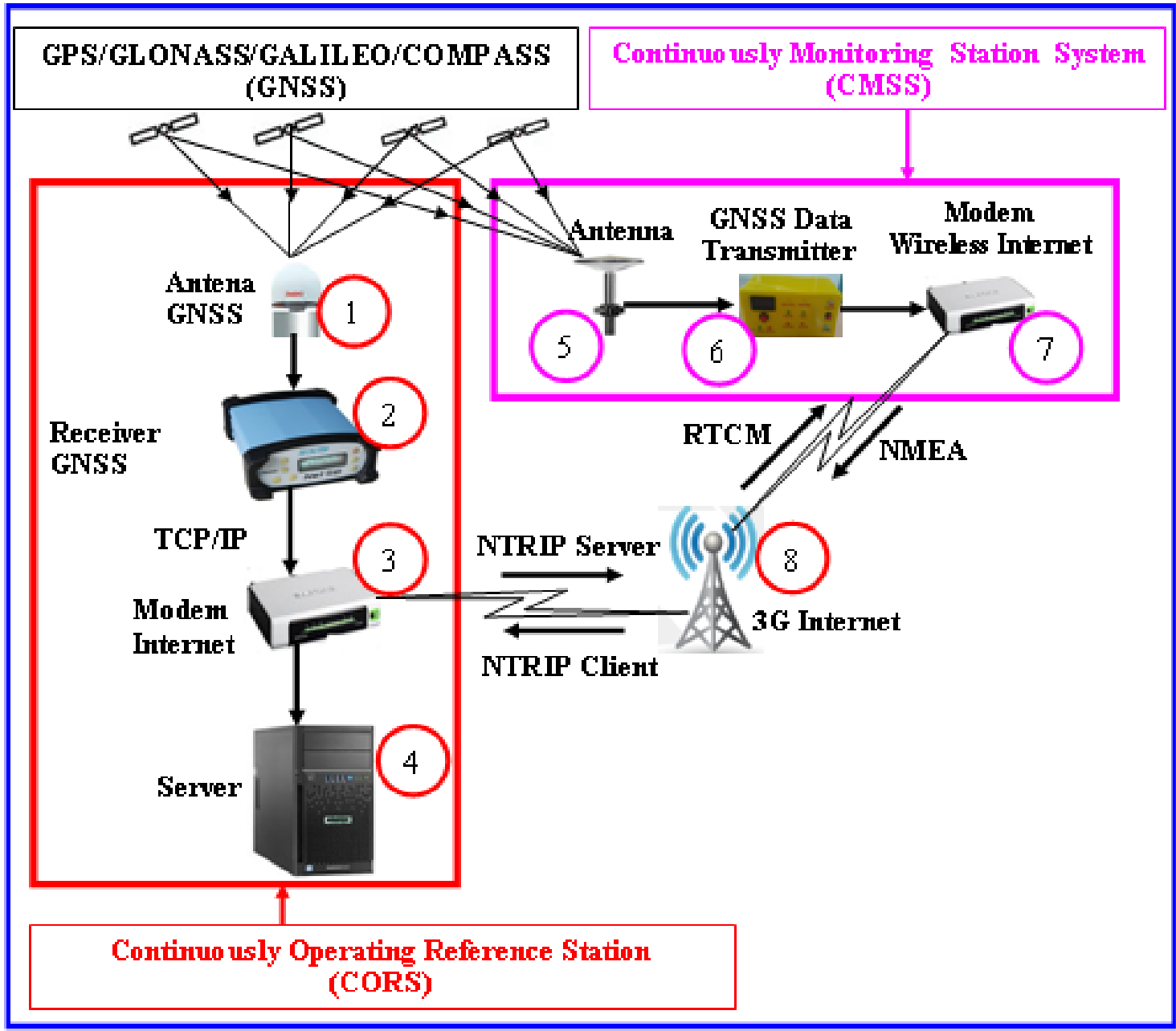

Hình 1. Sơ đồ nguyên lý hoạt động của hệ thống quan trắc chuyển dịch theo thò̀ gian thực 
động RTK, đồng thời hiệu chỉnh các số nguyên đa trị của toàn mạng, thiết lập mô hình cải chính (gồm cải chính sai số tầng đối lưu, tầng điện ly, quỹ đạo vệ tinh). Các số liệu ở trạm CORS được thu liên tục với tần suất $1 \mathrm{~Hz}$ và được thiết đặt trong phần mềm điều khiển trung tâm. Số liệu được lưu trữ trong một thư mục nhất định trong máy chủ theo chuẩn định dạng của tệp RINEX.

Việc quan trắc chuyển dịch được thực hiện theo phương thức đo động xử lý tức thời RTK (Real Time Kinematic). Trạm sử dụng là máy thu GNSS đa tần có khe lắp sim điện thoại đặt ở trạm quan trắc, kết nối đến trạm CORS và gửi tọa độ gần đúng đến trạm chủ thông qua chuỗi số liệu đo có định dạng chuẩn dũ liệu của NMEA (National Marine Electronics Association - Hiệp hội điện tử hàng hải quốc gia, Mỹ) (http://igs.bkg.bund .de/root_ftp/NTRIP/documentation/NtripDocu mentation.pdf/). Trạm chủ sau khi nhận được tọa độ gần đúng sẽ tính toán được với mạng viễn thông để truyền số liệu thông qua phần mềm chuyên dụng cài đặt trong sổ đo điện tử (Fieldbook). Số liệu đo của trạm sử dụng được gửi về trạm chủ theo định dạng chuẩn dữ liệu của NMEA (National Marine Electronics Association Hiệp hội điện tử hàng hải quốc gia, Mỹ).

Tại máy chủ có cài đặt một phần mềm với tên gọi NRS - Server sẽ tính toán và xác định số cải chính cho trạm sử dụng và xác định được tọa độ chính xác cho trạm sử dụng và truyền đi theo định dạng dữ liệu RTCM (http://igs.bkg.bund.de/root_ $\mathrm{ftp} / \mathrm{NTRIP} /$ documentation/ NtripDocumentation .pdf/ ) nhờ thiết bị thu nhận và truyền dẫn số liệu (GNSS Data Transmitter) được tác giả nghiên cứu, thiết kế, phát triển. Tọa độ của trạm quan trắc được tính theo công thức (1):

$$
\left\{\begin{array}{l}
X_{M}=X_{M}(t)+\delta x(t) \\
Y_{M}=Y_{M}(t)+\delta y(t) \\
Z_{M}=Z_{M}(t)+\delta z(t)
\end{array}\right.
$$

Trong đó: $X_{M}, Y_{M}, Z_{M}$ là toạ độ của trạm quan trắc cần xác định trong hệ toạ độ thực dụng của trạm CORS ; $X_{M}(t), Y_{M}(t), Z_{M}(t)$ là toạ độ định vị tuyệt đối của trạm quan trắc ở thời điểm $t ; \delta x(t), \delta y(t), \delta z(t)$ là số cải chính cho trạm quan trắc được xác định theo công thức (2):

$$
\left\{\begin{array}{l}
\delta x(t)=X_{C O R S}-X_{C O R S}(t) \\
\delta y(t)=Y_{C O R S}-Y_{\text {CORS }}(t) \\
\delta z(t)=Z_{C O R S}-Z_{C O R S}(t)
\end{array}\right.
$$

Trong đó: $X_{C O R S}, Y_{C O R S}, Z_{C O R S}$ là toạ độ đã biết trong hệ toạ độ thực dụng của trạm CORS; $X_{C O R S}(t)$, $Y_{\text {CORS }}(t), Z_{\text {CORS }}(t)$ là toạ độ định vị tuyệt đối của trạm CORS ở thời điểm $t$.

Cơ chế truyền dẫn số liệu cải chính và tin nhắn trị đo theo định dạng của hiệp hội điện tử quốc gia Mỹ (National Marine Electronics Association NMEA) được thực hiện theo phương thức NTRIP (Network Transport of RTCM via Internet Protocol) trên nền mạng IP (http://igs.bkg. bund.de/root_ftp/NTRIP/documentation/NtripD ocumentation.pdf/). Phương thức truyền dẫn số liệu của mạng lưới trạm CORS theo giao thức NTRIP được thể hiện như Hình 2.

\section{Thiết kế hệ thống quan trắc liên tục mái đào nhà máy thủy điện xekaman 3 theo công nghệ GNSS CORS}

\subsection{Giới thiệu về công trình}

Công trình thủy điện Xekaman 3 được khởi công xây dựng vào năm 2006 và hoàn thành vào

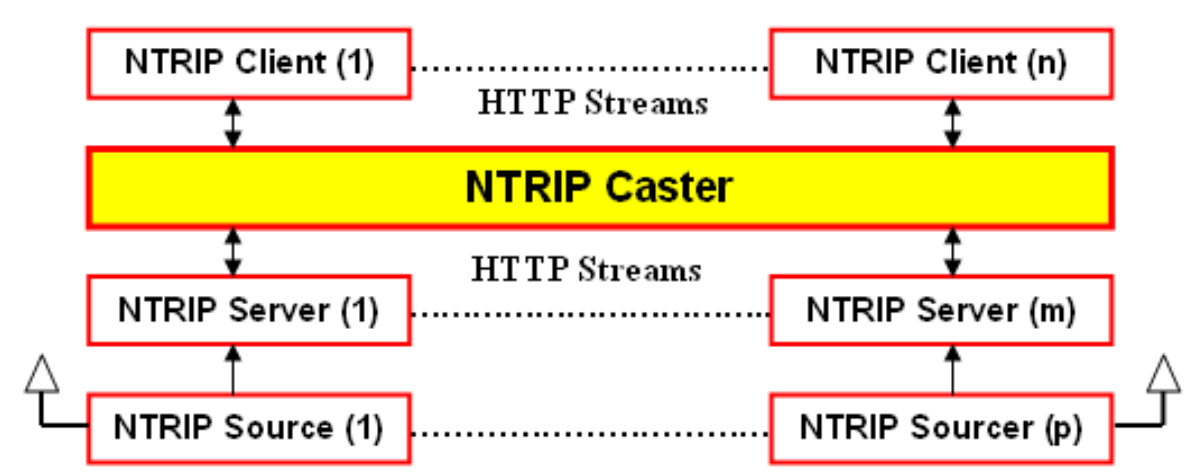

Hình 2. Phương thức truyền dẫn số liệu của trạm CORS theo giao thức NTRIP. 
năm 2013, nằm trên dòng Nậm - pa - nu, nhánh chính của Sông Xekaman, chi lưu của sông Sê Kông. Công trình thuộc địa phận huyện Đắc Chưng, tỉnh Sê Kông nước Cộng hòa Dân chủ Nhân dân Lào, cách biên giới Việt - Lào qua cửa khẩu Nam Giang - Đăk Ta Oóc khoảng 40 km. Thủy điện Xekaman 3 dẫn nước đến tổ máy phát điện bằng đường ống có đường kính $4 \mathrm{~m}$, chiều dài hơn $7 \mathrm{~km}$ đi sâu dưới lòng đất. Do ảnh hưởng của cấu trúc địa chất và địa hình cũng như quá trình thi công phần mái dốc phía trên nhà máy làm xuất hiện một khối trượt lớn có nguy cơ ảnh hưởng đến nhà máy phát điện (Hình 3). Để đảm bảo an toàn cho người và thiết bị của nhà máy, một giải pháp công nghệ quan trắc trượt lở theo thời gian thực đã được nghiên cứu.

\subsection{Thiết kế bố trí trạm quan trắc}

Dựa trên quy mô của nhà máy, yêu cầu của công tác quan trắc, thời gian quan trắc, đặc điểm về cấu trúc địa chất, diện tích vùng trượt lở và khối lượng đất đá trong phạm vi có nguy cơ trượt lở và yêu cầu của nhà thầu liên doanh Việt - Lào bố trí 18 trạm quan trắc. Các trạm quan trắc này được thiết kế trên bản đồ địa hình tỷ lệ 1:10.000 và phân bố đều trong vùng có nguy cơ trượt lở cao (Hình 4).

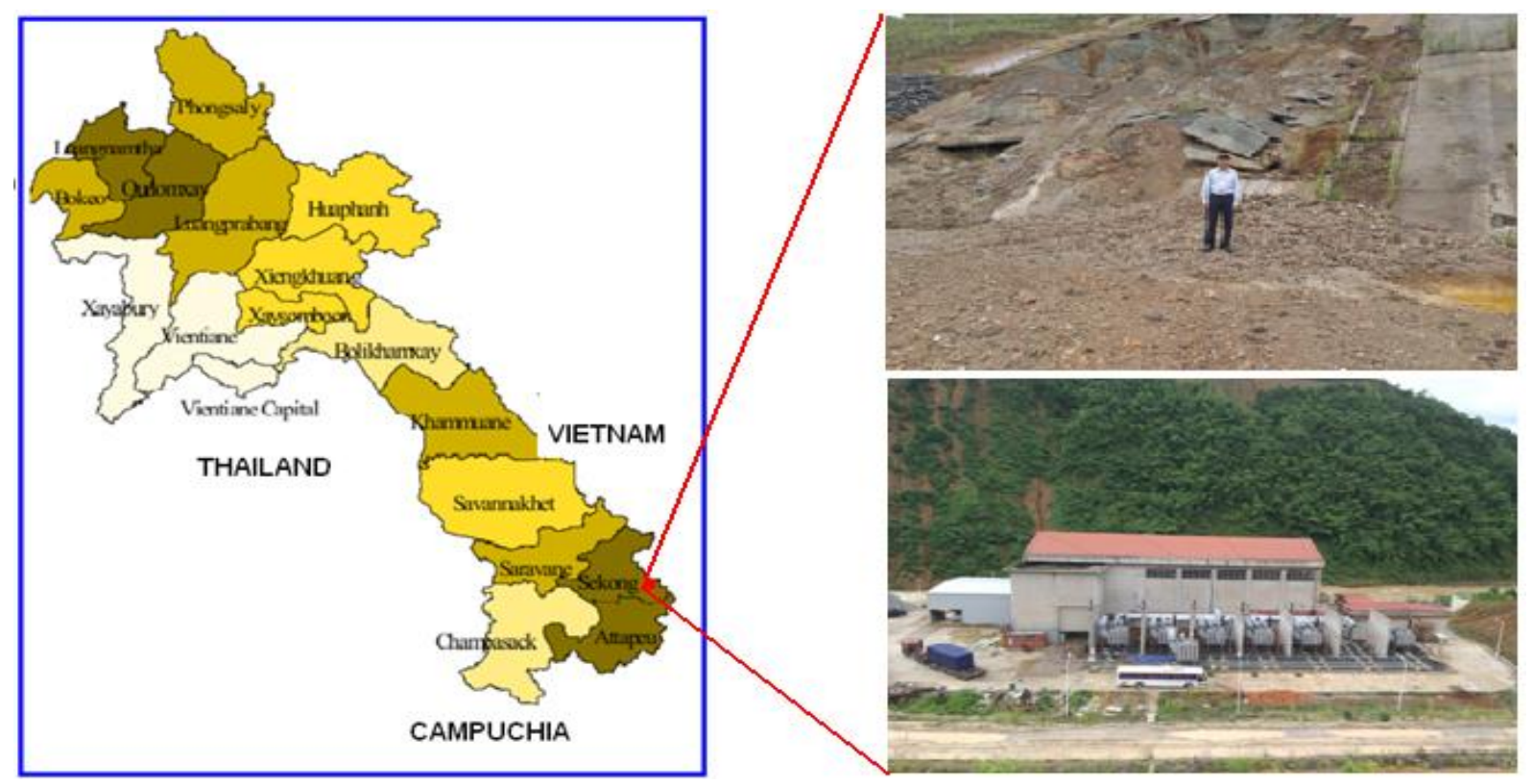

Hình 3. Vị trí nhà máy thủy điện Xekaman 3 và khối trượt.
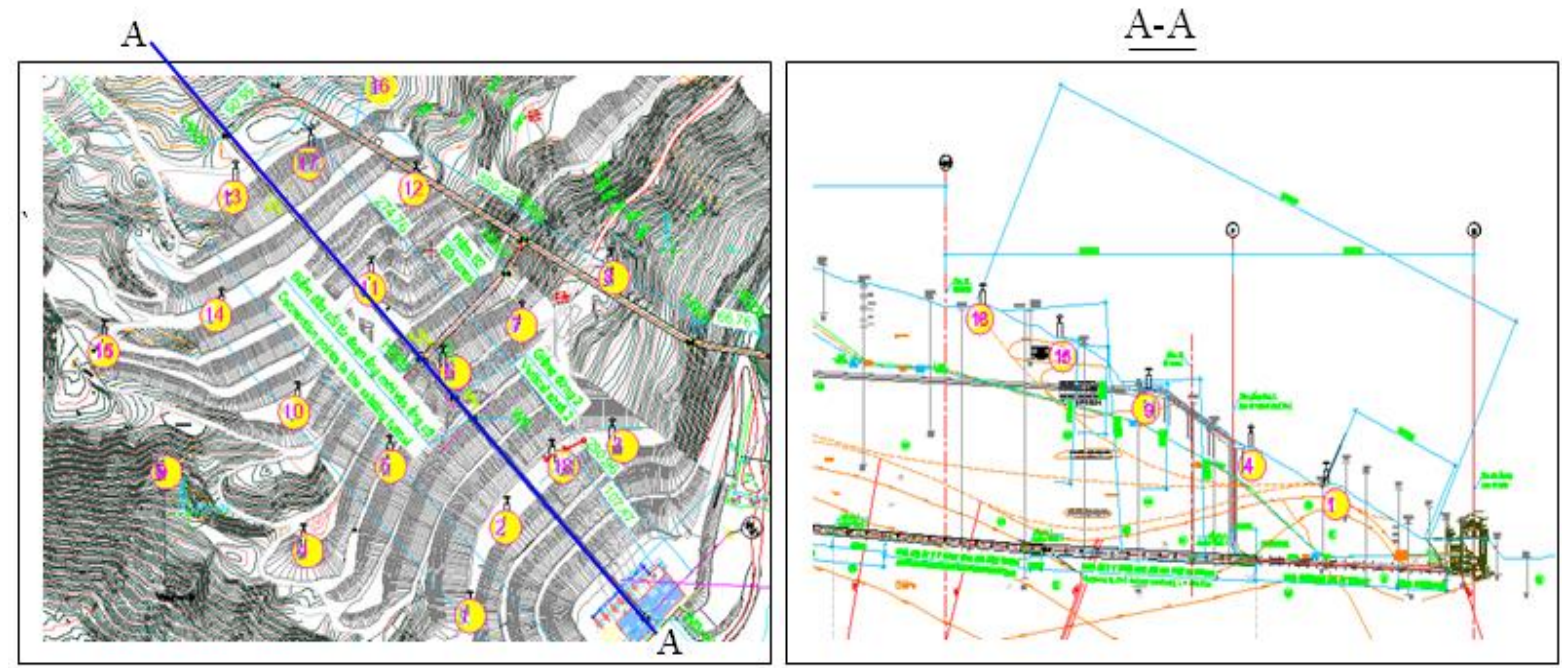

Hình 4. So đồ bố trí các trạm quan trắc. (a) Bình đồ bố trí trạm quan trắc; (b)mắt cắt địa chất theo tuyến dẫn nước. 


\subsection{Thiết kế mạng lưới truyền dẫn số liệu cho hệ thống các trạm quan trắc}

Việc truyền dẫn số liệu của hệ thống quan trắc theo công nghệ GNSS CORS thường được thực hiện qua giao thức NTRIP (Hình 2). Số liệu được truyền dẫn qua mạng internet và qua sóng viễn thông 3G (4G hoặc 5G). Tuy nhiên, do nhà máy thủy điện Xekaman 3 nằm ở khu vực chưa có sóng viễn thông, vì vậy giải pháp cho việc truyền dẫn số liệu là sử dụng đường truyền internet. Sơ đồ thiết kế mạng lưới truyền dẫn số liệu cho toàn bộ hệ thống các trạm quan trắc được thể hiện như ở Hình 5.

\subsection{Thiết kế kết nối thiết bị ở một trạm quan trắc}

Các bộ phận thiết bị ở trạm quan trắc phải được kết nối để đảm bảo thu nhận được số liệu quan trắc liên tục với tần suất thu số liệu ít nhất là 1 giây thu một thông tin trị đo sau đó được xử lý và đưa ra cảnh báo tức thời bằng âm thanh, hình ảnh (đèn cảnh báo) để nhận biết được tình trạng, mức độ trượt lở đất đá. Hệ thống thiết bị và sơ đồ kết nối ở một trạm quan trắc được thiết kế như ở Hình 6.

Trong các thiết bị ở trạm quan trắc bộ thu GNSS (2) được nghiên cứu phát triển bởi tác giả (Phạm

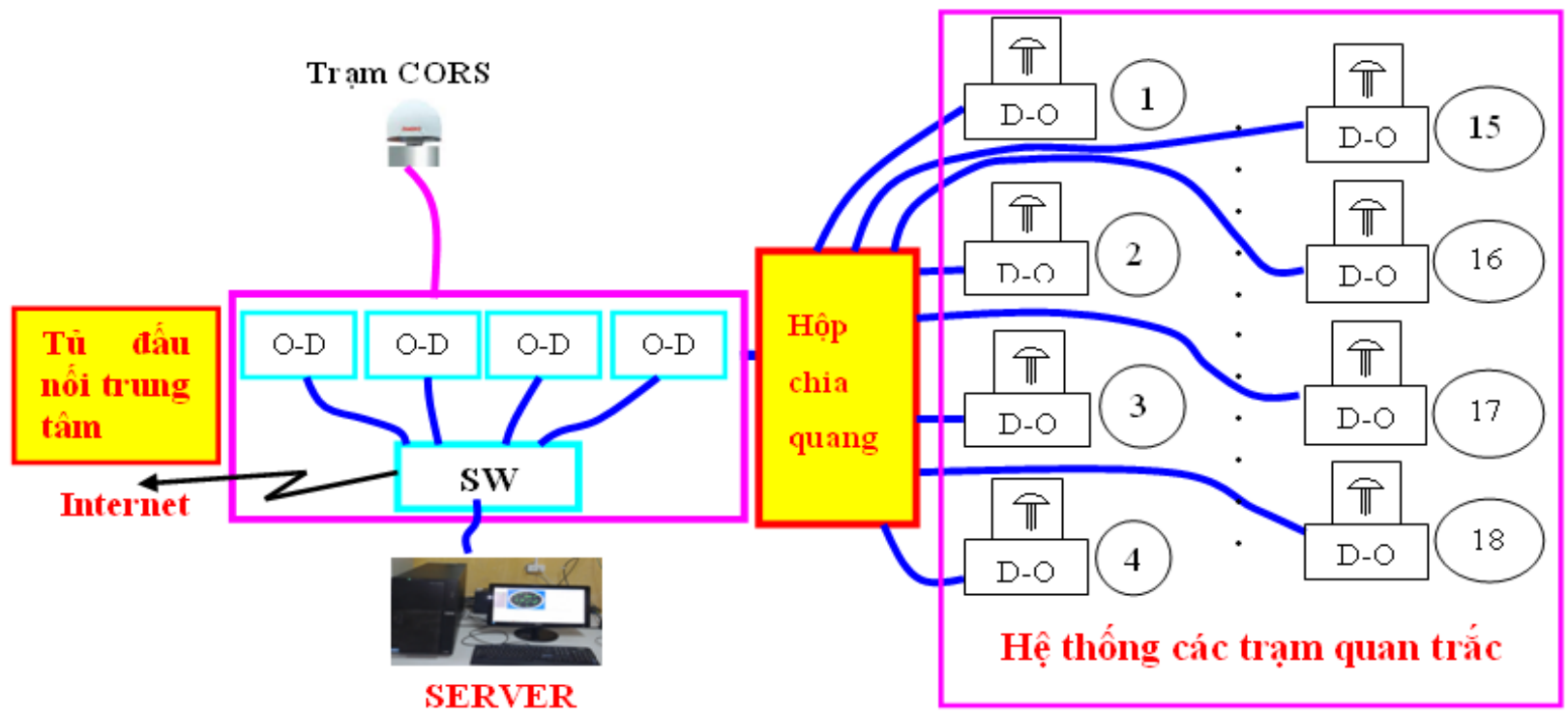

Hình 5. Sơ đồ thiết kếmạng lưới truyền dẫn số liệu của hệ thống quan trắc.
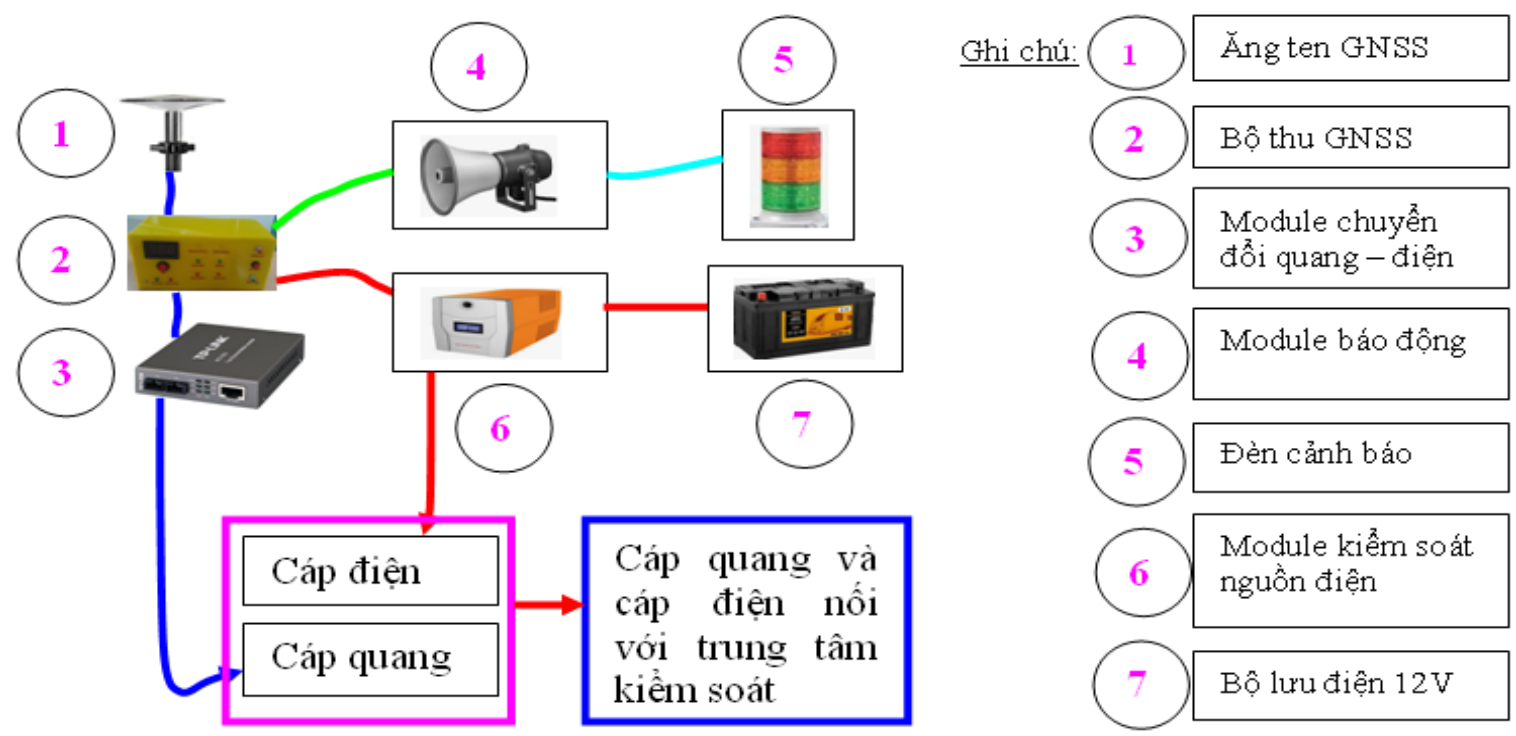

Hình 6. So đồ thiết kế kết nối thiết bị ở một trạm quan trắc. 
Công Khải và nnk., 2019). Thiết bị này có thể thu tín hiệu cả bốn hệ thống vệ tinh GPS, GLONASS, GALILEO, BEIDOU với 220 kênh. Phần thi công lắp đặt các thiết bị cho trạm quan trắc được thiết kế bằng phần mềm AutoCAD và được thể hiện như Hình 7.

\section{Thực nghiệm mô phỏng}

Để kiểm chứng sự hoạt động cũng như độ tin cậy của hệ thống quan trắc đã được thiết kế, một thực nghiệm mô phỏng dựa trên một hệ thống thiết bị đã được thiết kế, chế tạo gồm một đường ray nằm ngang có gắn một thước thép để xác định chuyển dịch ngang và một thước thép gắn vào mốc hình trụ thẳng đứng để xác định dịch chuyển đứng. Phía dưới của mốc quan trắc có gắn 4 bánh xe, có thể chuyển dịch trên đường ray. Thiết bị quan trắc gồm một ăng ten thu tín hiệu vệ tinh GNSS, một bộ thu và truyền dẫn số liệu GNSS đã được phát triển, modem Internet, ắcquy, tấm pin năng lượng mặt trời và các phụ kiện kèm theo. Ăng ten GNSS được đặt cố định lên mốc quan trắc và nối với bộ thu nhận bằng cáp chuyên dụng. Sử dụng trạm CORS - N001 lắp đặt ở Trường đại học Mỏ - Địa chất để truyền số cải chính cho trạm quan trắc thông qua địa chỉ IP: 118.70.171.179 và cổng kết nối 6061. Hệ thống đường ray được đặt trên một mặt dốc và gần song song với trục $O Y$ (Hình 8). Để thu nhận, xử lý số liệu và đưa ra cảnh báo, một phần phần mềm tự thiết kế xây dựng có tên SERVER GNSS CORS WDM (Hình 9) được cài đặt ở máy chủ.

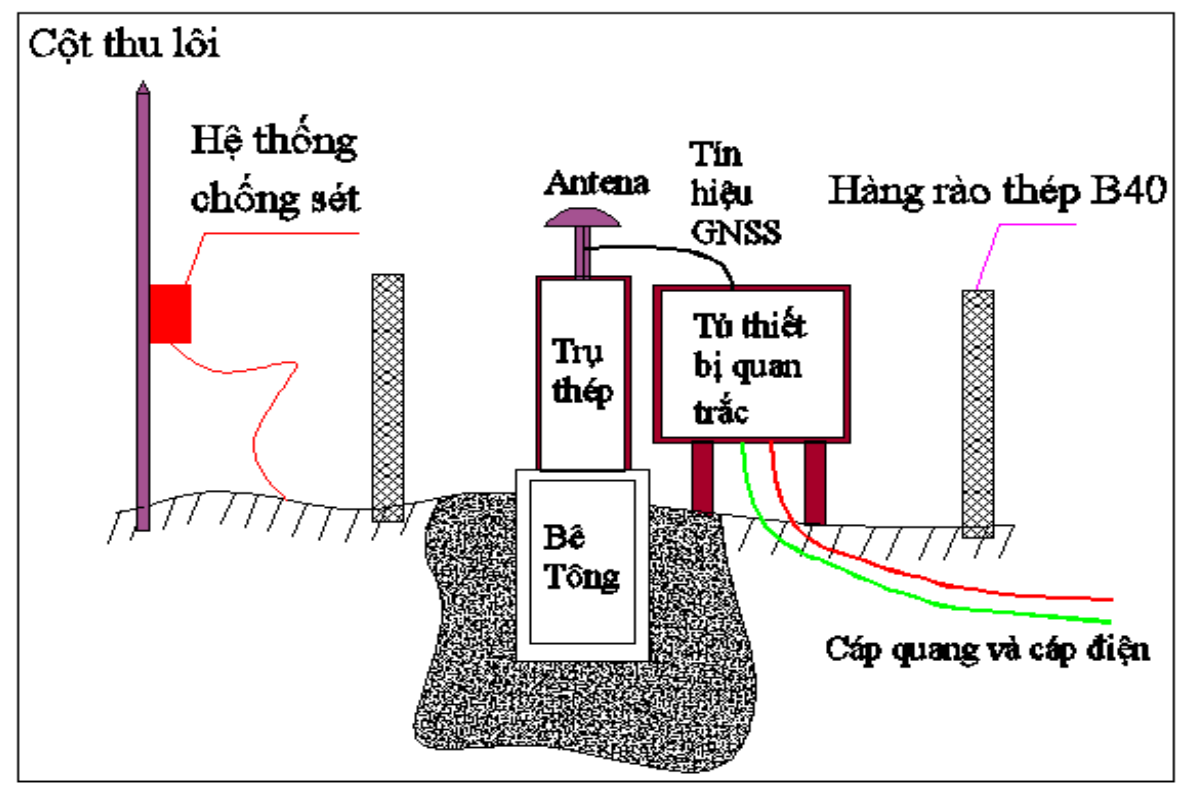

Hình 7. Bản vẽ thiết kế thi công lắp đặt thiết bị cho trạm quan trắc.

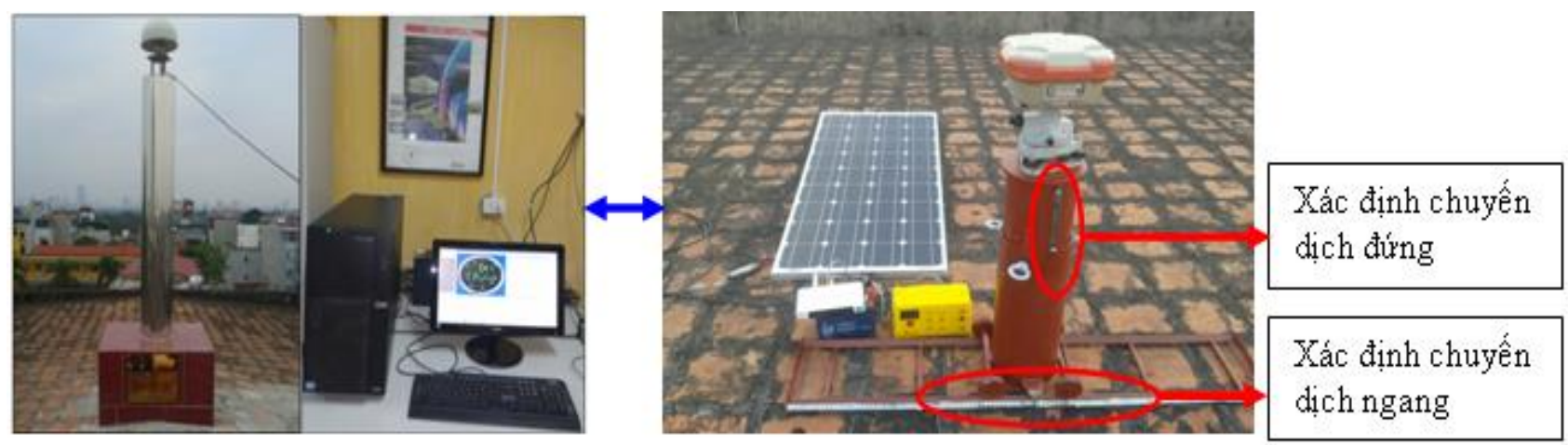

Hình 8. Hệ thống thực nghiệm mô phỏng quan trắc trượt lở đất đá theo thòi gian thực.

(a) Hệ thống trạm CORS; (b) Hệ thống trạm quan trắc. 
Việc thực nghiệm mô phỏng hệ thống quan trắc được tiến hành vào ngày 30 tháng 10 năm 2019. Các thiết bị của trạm quan trắc sau khi được lắp đặt, bật công tắc nguồn, hệ thống sẽ tự động làm việc sau 15 giây. Ăng ten thu tín hiệu vệ tinh GNSS và truyền về bộ thu, ở đây tín hiệu được giải mã thành dữ liệu theo tiêu chuẩn NMEA và truyền về máy chủ thông qua mạng viễn thông 3G. Sau đó dịch chuyển mốc quan trắc có đặt ăng ten đi một khoảng cách nhất định. Đại lượng dịch chuyển của mốc quan trắc này được xác định dựa vào thước thép gắn trên mốc quan trắc (đại lượng này dùng để kiểm tra), sau đó dựa vào số liệu quan trắc ở hai thời điểm để xác định đại lượng dịch chuyển. Một đoạn số liệu thu được ở trạm quan trắc theo tiêu chuẩn NMEA ở dạng GGA được thể hiện như ở Bảng 1.

Từ số liệu quan trắc như ở Bảng 1 , lọc ra để lấy các giá trị tọa độ đã được cải chính từ trạm CORS. Từ các giá trị tọa độ đó trong hệ tọa độ WGS84, tính đổi sang tọa độ VN 2000 theo công thức (3), (Phạm Hoàng Lân và nnk., 2017).

$$
\left\{\begin{array}{l}
X=\Delta X_{0}+k\left(X^{\prime}+\varepsilon_{0} Y^{\prime}-\Psi_{0} Z^{\prime}\right) \\
Y=\Delta Y_{0}+k\left(-\varepsilon_{0} X^{\prime}+Y^{\prime}+\omega_{0} Z^{\prime}\right) \\
Z=\Delta Z_{0}+k\left(\Psi_{0} X^{\prime}-\omega_{0} Y^{\prime}+Z^{\prime}\right.
\end{array}\right.
$$

Trong đó: $X, Y, Z$ là tọa độ vuông góc không gian trong hệ tọa độ $\mathrm{VN}-2000,(\mathrm{~m}) ; X^{\prime}, Y^{\prime}, Z^{\prime}$ là tọa độ vuông góc không gian trong hệ tọa độ WGS - 84, (m); $\Delta X_{o}, \Delta Y_{o}, \Delta Z_{o}$ là các tham số dịch chuyển gốc tọa độ $(\mathrm{m}) ; \omega_{o}, \psi_{o}, \varepsilon_{o}$ là 3 góc xoay trục tọa độ tương ứng với các trục $X, Y, Z$, ( radian); $k$ là hệ số tỷ lệ chiều dài giữa 2 hệ.

Các tham số tính đổi tọa độ từ hệ WGS - 84 sang hệ tọa độ VN - 2000 do Bộ Tài nguyên và Môi trường công bố, (Quyết định 05/2007/QĐ BTNMT).

Giá trị tọa độ của trạm quan trắc sau khi tính đổi sang hệ tọa độ VN2000, tính ra giá trị trung bình cho từng thởi điểm quan trắc. Độ dịch chuyển theo trục $\mathrm{X}$, theo trục $\mathrm{Y}$ và dịch chuyển toàn phần được xác định bằng hiệu tọa độ giữa hai thời điểm quan trắc, được xác định theo các công thức sau:

- Chuyển dịch theo trục $O X$ :

$$
Q X=X^{i+1}-X^{i}
$$

- Chuyển dịch theo trục $\mathrm{OY}$ :

$$
Q y=Y^{i+1}-Y^{i}
$$

- Chuyển dịch toàn phần:

$$
Q=\sqrt{Q_{X}^{2}+Q_{Y}^{2}}
$$

Trong Bảng 2 thể hiện giá trị chuyển dịch ngang xác định bằng thiết bị quan trắc và được đo trực tiếp bằng thước thép gắn trên mốc quan trắc, độ chênh lệch về chuyển dịch ngang lớn nhất là 3.3 $\mathrm{mm}$, nhỏ nhất là $2.2 \mathrm{~mm}$.

Như vậy bằng hệ thống quan trắc đã được nghiên cứu thiết kế hoàn toàn có thể ứng dụng vào trong công tác quan trắc chuyển dịch mái dốc ở nhà máy thủy điện Xekaman 3 nói riêng và các đối tượng trên mặt đất nói chung.

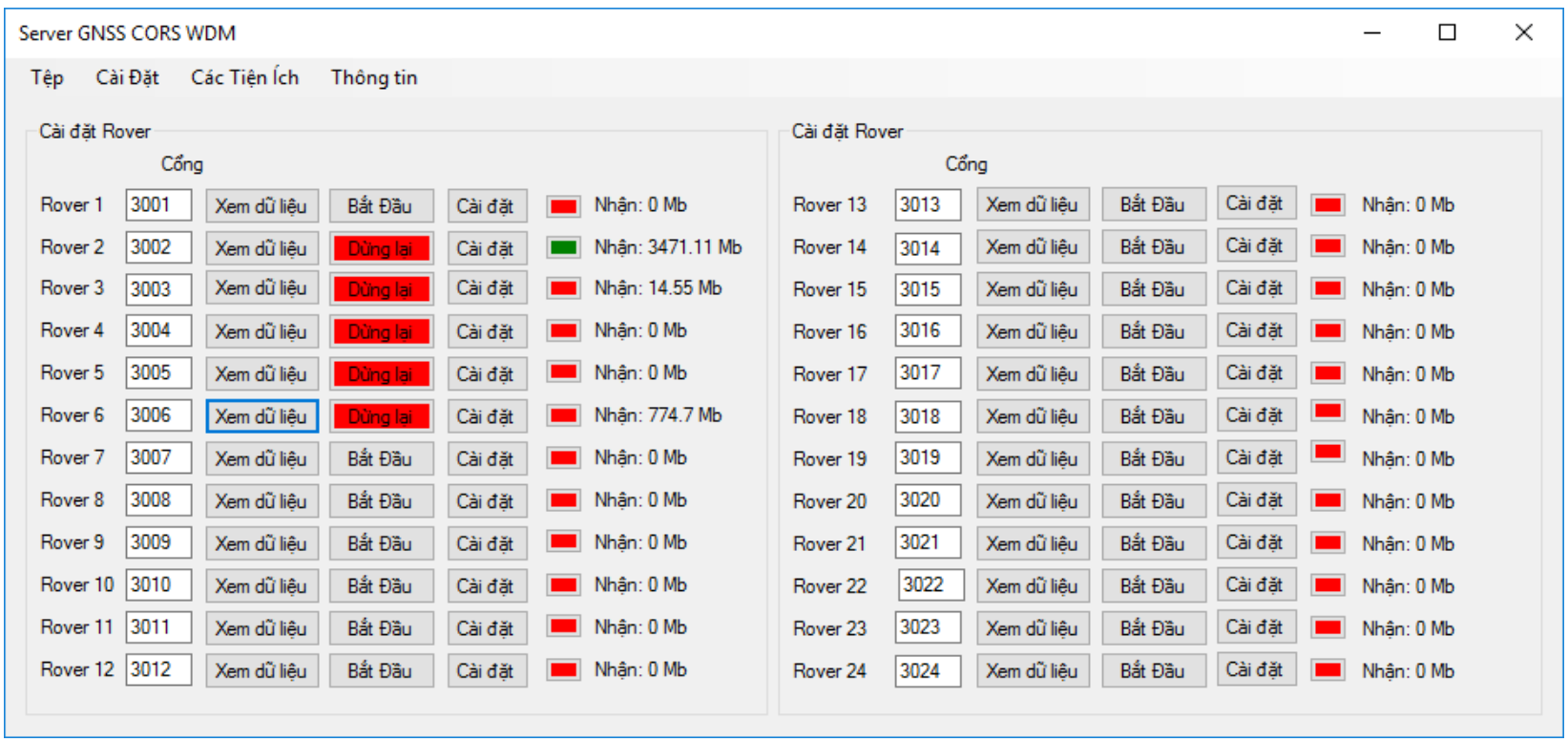

Hình 9. Phần mềm thu nhận và xử lý số liệu quan trắc. 
Bảng 1. Số liệu quan trắc theo tiêu chuẩn NMEA ở dạng GGA.

\begin{tabular}{c}
\hline \$GNGGA,165942.00,2102.85446077,N,10547.23253617,E,4,20,0.7,25.588,M, - 28.232,M,1.0,0000*4E \\
\hline \$GNGGA,165943.00,2102.85446077,N,10547.23253618,E,4,20,0.7,25.589,M, - 28.232,M,1.0,0000*41 \\
\hline \$GNGGA,165944.00,2102.85446071,N,10547.23253619,E,4,20,0.7,25.588,M, - 28.232,M,1.0,0000*40 \\
\hline \$GNGGA,165945.00,2102.85446066,N,10547.23253624,E,4,20,0.7,25.588,M, - 28.232,M,1.0,0000*49 \\
\hline \$GNGGA,165946.00,2102.85446071,N,10547.23253623,E,4,20,0.7,25.588,M, - 28.232,M,1.0,0000*4B \\
\hline \$GNGGA,165947.00,2102.85446070,N,10547.23253634,E,4,20,0.7,25.588,M, - 28.232,M,1.0,0000*4D \\
\hline \$GNGGA,165948.00,2102.85446071,N,10547.23253633,E,4,20,0.7,25.588,M, - 28.232,M,1.0,0000*44 \\
\hline \$GNGGA,165949.00,2102.85446065,N,10547.23253632,E,4,20,0.7,25.588,M, - 28.232,M,1.0,0000*41 \\
\hline \$GNGGA,165950.00,2102.85446073,N,10547.23253629,E,4,20,0.7,25.588,M, - 28.232,M,1.0,0000*44 \\
\hline \$GNGGA,165951.00,2102.85446071,N,10547.23253623,E,4,20,0.7,25.588,M, - 28.232,M,1.0,0000*4D \\
\hline \$GNGGA,165952.00,2102.85446068,N,10547.23253630,E,4,20,0.7,25.588,M, - 28.232,M,1.0,0000*44 \\
\hline \$GNGGA,165953.00,2102.85446063,N,10547.23253625,E,4,20,0.7,25.588,M, - 28.232,M,1.0,0000*4A \\
\hline \$GNGGA,165954.00,2102.85446064,N,10547.23253628,E,4,20,0.7,25.588,M, - 28.232,M,1.0,0000*47 \\
\hline \$GNGGA,165955.00,2102.85446060,N,10547.23253628,E,4,20,0.7,25.588,M, - 28.232,M,1.0,0000*42 \\
\hline \$GNGGA,165956.00,2102.85446059,N,10547.23253622,E,4,20,0.7,25.589,M, - 28.232,M,1.0,0000*40 \\
\hline \$GNGGA,165957.00,2102.85446051,N,10547.23253633,E,4,20,0.7,25.588,M, - 28.232,M,1.0,0000*48 \\
\hline \$GNGGA,165958.00,2102.85446061,N,10547.23253629,E,4,20,0.7,25.588,M, - 28.232,M,1.0,0000*4F \\
\hline \$GNGGA,165959.00,2102.85446060,N,10547.23253626,E,4,20,0.7,25.588,M, - 28.232,M,1.0,0000*40 \\
\hline
\end{tabular}

Bảng 2. Xác định và đánh giá độ chính xác kết quả quan trắc chuyển dịch ngang.

\begin{tabular}{|c|c|c|c|c|c|c|c|}
\hline \multirow{2}{*}{$\begin{array}{l}\text { Lần } \\
\text { quan } \\
\text { trắc }\end{array}$} & \multicolumn{2}{|c|}{ Tọa độ (m) } & \multicolumn{3}{|c|}{ Chuyển dịch (mm) } & \multirow{2}{*}{$\begin{array}{l}\text { Chuyển dịch đo } \\
\text { trực tiếp (mm) }\end{array}$} & \multirow{2}{*}{$\begin{array}{l}\text { Chênh lệch } \\
\text { (mm) }\end{array}$} \\
\hline & $\mathrm{X}$ & Y & Theo trục X & Theo trục Y & $\begin{array}{l}\text { Toàn } \\
\text { phần }\end{array}$ & & \\
\hline \multirow[t]{2}{*}{1} & 2330873.1892 & 580572.4845 & - & - & - & - & - \\
\hline & - & - & 1.9 & 19.6 & 19.7 & 23.0 & 3.3 \\
\hline \multirow[t]{2}{*}{2} & 2330873.1911 & 580572.5041 & - & - & - & - & - \\
\hline & - & \begin{tabular}{|l|}
- \\
\end{tabular} & 3.4 & 34.2 & 34.4 & 31.5 & 2.9 \\
\hline \multirow[t]{2}{*}{3} & 2330873.1945 & 580572.5383 & - & - & - & - & - \\
\hline & - & - & 3.3 & 42.9 & 43.0 & 40.0 & 3.0 \\
\hline \multirow[t]{2}{*}{4} & 2330873.1978 & 580572.5812 & - & - & - & - & - \\
\hline & - & - & 3.2 & 54.4 & 54.5 & 57.0 & 2.5 \\
\hline \multirow[t]{2}{*}{5} & 2330873.2010 & 580572.6356 & - & - & - & - & - \\
\hline & - & - & 4.2 & 59.7 & 59.8 & 62.0 & 2.2 \\
\hline 6 & 2330873.2052 & 580572.6953 & - & - & - & - & - \\
\hline
\end{tabular}

\section{Kết luận}

Trượt lở đất đá ở nhà máy thủy điện Xekaman 3 đã xảy ra làm thiệt hại rất lớn về tài sản, mặc dù ở nhà máy đã có hệthống quan trắc bằng máy toàn đạc điện tử nhưng là quan trắc theo chu kỳ nên không thể đưa ra cảnh báo theo thời gian thực. Với ứng dụng của công nghệ GNSS CORS việc quan trắc theo thời gian thực trượt lở đất đá ở nhà máy thủy điện Xekaman 3 đã được nghiên cứu thiết kế với 18 trạm quan trắc bố trí trên bề mặt và 01 trạm CORS. Một mạng lưới truyền dẫn số liệu quan trắc quan trắc và truyền dẫn số liệu cải chính của trạm CORS đã được thiết kế bằng đường truyền internet cáp quang tốc độ cao. Một sơ đồ kết nối các thiết bị ở trạm quan trắc và bản vẽ thi công xây dựng trạm quan trắc đã được thiết kế.

Thực nghiệm mô phỏng quan trắc chuyển dịch theo thời gian thực đã được tiến hành với trạm CORS - N001 và hệ thống trạm quan trắc đã thiết kế phát triển cả về phần cứng và phần mềm cho 
phép xác định được độ chuyển dịch nhỏ nhất đến $2.2 \mathrm{~mm}$ và cảnh báo tức thời bằng hệ thống âm thanh và ánh sáng để dễ dàng nhận biết.

\section{Tài liệu tham khảo}

Bộ Tài nguyên và Môi trường, (2007). Quyết định 05/2007/QĐ - BTNMT về sử dụng hệ thống tham số tính chuyển giữa hệ tọa độ quốc tế WGS - 84 và hệ tọa độ quốc gia VN - 2000.

Georgieva, K., Smarsly, K.,König M., and Law, K. H., (2015). An Autonomous Landslide Monitoring System Based on Wireless Sensor Networks. https://www.researchgate.net/publication/2 68438328.

Irwan Gumilar, Alif Fattah, Hasanuddin Z. Abidin, Vera Sadarviana, Nabila S. E. Putri, and Kristianto (2017). Landslide monitoring using terrestrial laser scanner and robotic total station in Rancabali. West Java (Indonesia).

Kuang, K. S. C., Qinghao Cao, (2015). A Low - Cost, Wireless Chemiluminescence - Based Deformation Sensor for Soil Movement and Landslide Monitoring.

National Marine Electronics Association: http://www.nmea.org

Networked Transport of RTCM via Internet Protocol (Ntrip) , Version 1.0. In: GDC (GNSS Data Center) [online]. Bundesamt für Kartographie und Geodäsie (BKG), 2004. [cit.26.05.2016]. Available from: http://igs.bkg.bund.de/root_ftp/NTRIP/docu mentation/NtripDocumentation.pdf/

Phạm Công Khải, (2019). Nghiên cứu phương pháp quan trắc liên tục sự dịch chuyển và biến dạng công trình trên địa bàn thành phố Hà Nội. Báo cáo tổng hợp kết quả nghiên cứu đề tài cấp thành phố. Mã số 01C-04/08-2016-3. Sở Khoa học và Công nghệ Hà Nội.

Phạm Hoàng Lân, Đặng Nam Chinh, Dương Vân Phong, Vũ Văn Trí, (2017). Trắc địa cao cấp đại cương. Nhà xuất bản Giao thông vận tải. Hà Nội.

Ruya Xiao, Xiufeng He, (2013). Real - time landslide monitoring of Pubugou hydropower resettlement zone using continuous GPS. ttps://www.researchgate.net/publication/25 7633559.

Savvaidis, 2016. Existing Landslide Monitoring Systems and Techniques. Journal of Measurement. 242 - 258.

Serena Artese, Michele Perrelli, (2018). Monitoring a Landslide with High Accuracy by Total Station: A DTM - Based Model to Correct for the Atmospheric Effects. www.mdpi.com/journal/geosciences.

Tommaso Carlàa, Veronica Tofania, Luca Lombardia, Federico Raspinia, Silvia Bianchinia, Davide Bertolob, Patrick Thuegazb, Nicola Casagli (2019). Combination of GNSS, satellite InSAR, and GBInSAR remote sensingmonitoring to improve the understanding of a large landslide in highalpine environment. Geomorphology. 62 75.

Vu Van Khoa, Shigeru Takayama, (2018). Wireless sensor network in landslide monitoring system with remote data management. Journal of Measurement. 214 - 229. 